\title{
Globalization, inequality and economic policy ${ }^{1}$
}

\section{Udo Broll $^{2}$, Alexander Kemnitz ${ }^{3}$, Vivekananda Mukherjee ${ }^{4}$}

\begin{abstract}
In our paper a very simple model is used to analyze the relationship between trade globalization, inequality and economic policy. Although the local government exclusively maximizes the welfare of the marginalized (unemployed) people, the inequality of relative consumption between employed and unemployed will increase with intensified trade liberalization. In contrast to this result the relative income inequality may fall in certain situations.
\end{abstract}

Keywords: globalization, inequality, marginalization, economic policy, public policy.

JEL codes: D30, F61, F68, I30, H2.

\section{Introduction}

This paper addresses the question of how trade globalization affects the distribution of income within a small open economy and the income of the poorest segment of the population (marginalized) in particular. There is much literature which refers to wealth, income and consumption inequality in open economies (see Alvaredo, Chancel, Piketty, Saez, \& Zucman, 2018; Atkinson, 2015; Basu, 2006, 2011; Elbers, Lanjouw, Mistiaen, \& Ölzer, 2008; Jomo \& Baudot, 2007; OECD, 2015; Piketty, 2014; Rodrik, 2011).

Disparities in income are a problem from a social point of view. However it is also a problem from the political perspective. For example, large differences in income and wealth between European regions can hinder the process of European integration (Baldwin \& Wyplosz, 2015).

\footnotetext{
${ }^{1}$ Article received 23 November 2018, accepted 15 January 2019.

${ }^{2}$ Department of Business and Economics, School of International Studies (ZIS), Technische Universität Dresden, 01062 Dresden, Germany, udo.broll@tu-dresden.de (U. Broll). We would like to thank our referees and the editor of this journal for very helpful comments and suggestions.

${ }^{3}$ Department of Business and Economics, School of International Studies (ZIS), Technische Universität Dresden, 01062 Dresden, Germany.

${ }^{4}$ Department of Economics, Jadavpur University, Kolkata, India.
} 
This study asks questions about the effectiveness of domestic policies in favour of the marginalized, i.e. the 'left behind' by globalization. It is assumed that the local government maximizes exclusively the welfare of the unemployed people. What is the effect of such a redistributive policy on income and consumption inequalities? It is discovered that intensified trade globalization, even with such an extremely pro-marginalized government, the rise in the inequality in consumption can not be prevented, while income inequality may fall. The precise conditions for the rise or the fall of income inequality can be identified.

The paper is structured as follows: Section 1 presents a partial equilibrium model of a country having its population separated into two homogeneous groups of people: employed and unemployed (or marginalized). The unemployed are supported mainly by the income tax imposed on the income of employed people, which is supplemented by the tariff revenue. The tariff revenue is collected from the import of the commodites that are exclusively consumed by the employed consumers. Given the tariff rate and the tax rate the equilibrium levels of income and consumption of both groups can be determined. Section 2 demonstrates the relationship between trade liberalization, inequality within a nation and the welfare policy for the marginalized, i.e. the 'left behind' by globalization. The main results are obtained and discussed. The last section concludes.

\section{The model}

The interaction of trade globalization, inequality, labour supply and the welfare programme for the unemployed (i.e. marginalized) within the nation which has a small open economy is studied.. The population of the economy is fixed and is divided between two different groups: employed and unemployed (marginalized) people. The number of employed and unemployed are denoted as $e$ and $n$, respectively. Labour is a factor of production in the economy. In order to support the unemployed population the national government of the country runs a redistribution programme which taxes the income of the employed and transfers the proceeds to the marginalized. Income tax is proportional at the rate $t \in(0,1)$.

In addition to income tax the government has another source of revenue that comes from the imposition of tariffs on imported goods. The tariff revenue is exclusively collected from the employed people as they are the only ones to consume the imported commodity. As with the tax revenue the government does not necessarily redistribute the entire amount of tariff revenue to the unemployed. It redistributes a proportion $\gamma$ of the tariff revenue to the unemployed and $1-\gamma$ to the employed, respectively. ${ }^{5}$ For simplicity it is assumed that the

\footnotetext{
${ }^{5}$ As one of our referees suggested $\gamma$ can be a political tool and can be endogenous.
} 
economy imports only one commodity and exports a different good. Within the economy a non-traded good is produced. While the exported commodity is not consumed within the economy the non-traded commodity is consumed exclusively by the unemployed people.

The tariff inclusive price of the imported commodity is $p+\tau$; the world price of the commodity is denoted by $p$ and $\tau$ is the (most favoured nation) tariff per unit. $\tau$ is a parameter for the degree of "openness" of the economy. It is assumed that $\tau<p$. The economy being small in the international trade environment cannot control the world price. Neither can it control the value of $\tau$, which is determined as the part of international negotiations on the liberalization of trade. $\tau$ can be used as an index of the extent of globalization of the country. The lower the value of $\tau$, the more globalized is the economy.

Suppose $c_{e}$ is the consumption of the imported commodity by the representative employed individual; $w$ is his/her wage rate and $l$ is his/her consumption of leisure. The wage rate $w(\tau)$ is a decreasing function of the tariff rate $\tau$. As $\tau$ falls, the employed individual wishes to consume more of the imported good and therefore produces more of the exported commodity in which his/her productivity is higher and which has higher price on the world market. Therefore $\mathrm{w}$ rises. This is shown as a separate assumption.

Assumption (A.1)

$$
d w(\tau) / d \tau<0 .
$$

The budget constraint of the representative employed individual can be written as

$$
(p+\tau) c_{e}=w(\tau)(1-t)(T-l)+(1-\gamma) \tau c_{e^{\prime}}
$$

where $T$ is the endowment of time, i.e. 24 hours, and $l$ denotes leisure. The budget constraint can be rewritten as

$$
(p+\gamma \tau) c_{e}=w(\tau)(1-t)(T-l)
$$

For the employed individuals a utility function is assumed

$$
u\left(c_{\mathrm{e}}, l\right)=2 c_{e}^{1 / 2}+l .
$$

The representative employed individual maximizes $u\left(c_{e}, l\right)$ by choosing appropriate values of labour supply and consumption such that the budget constraint is satisfied. An interior solution is assumed for $c_{e}$ and $l$.

The per capita value of consumption, $c_{e}$, turns out to be

$$
c_{e}=\frac{[w(\tau)]^{2}(1-t)^{2}}{(p+\gamma \tau)^{2}} .
$$


The tax revenues are calculated as

$$
e t w(\tau)(T-l)=\frac{e t[w(\tau)]^{2}(1-t)}{p+\gamma \tau} .
$$

Furthermore the tariff revenues collected by the government read

$$
e \tau c_{e}=e \tau \frac{[w(\tau)]^{2}(1-t)^{2}}{(p+\gamma \tau)^{2}} .
$$

Therefore the per capita transfer of the local government to the marginalized, $S_{n}$, is given by

$$
S_{n}=\frac{e}{n}\left\{\frac{t[w(\tau)]^{2}(1-t)}{(p+\gamma \tau)}+\gamma \tau \frac{[w(\tau)]^{2}(1-t)^{2}}{(p+\gamma \tau)^{2}}\right\} .
$$

The per capita tariff revenue transfer to the employed, denoted by $S_{e^{e}}$, is

$$
S_{e}=(1-\gamma) \tau \frac{[w(\tau)]^{2}(1-t)^{2}}{(p+\gamma \tau)^{2}} .
$$

Since the marginalized population does not earn from the labour supply the only source of income for a representative unemployed individual is the transfer received from the government given by $y_{n}=S_{n}$. On the other hand, the per capita income of the employed, from the labuor supply as well as from the possible government transfer is

$$
y_{e}=w(\tau)(1-t)(T-l)+S_{e}
$$

Consider a representative unemployed individual. The price of the nontraded commodity he/she consumes is $p_{n}$. Observe, that $p_{n}(\tau)$ is a decreasing function of the tariff rate $\tau$. This is implied by assumption (A.1). Since the employed people also produce the non-traded commodity, as $\tau$ falls and consequently $w(\tau)$ rises, $p_{n}(\tau)$ also rises. This is noted separately in the following

Assumption (A.2)

$$
d p_{n}(\tau) / d \tau<0
$$

The income constraint of the representative unemployed individual can be written as $p_{n}(\tau) c_{n}=S_{n}$. Therefore per capita consumption is

$$
c_{n}=\frac{S_{n}}{p_{n}(\tau)} .
$$


The utility function of the representative unemployed individual takes the following form by assumption

$$
V\left(c_{n}\right)=2 c_{n}^{1 / 2}
$$

With substitution it is possible to ascertain the indirect utility function of a representative marginalized individual

$$
V=2\left[\frac{S_{n}(\tau, \gamma, p, t)}{p_{n}(\tau)}\right]^{1 / 2} .
$$

Now it is possible to discuss the relationship between globalization, inequality in income, consumption and policy. ${ }^{6}$ The aim of the next secti on is to study the possibility of a welfare policy for the marginalized in this economy.

\section{Tax and tariff revenues: redistribution}

The objective of this section is to analyze the interaction between globalization and inequality in income and consumption for the marginalized people. Questions are asked about the effectiveness of domestic policy instruments in favour of the marginalized. It is assumed that the domestic government maximizes exclusively the welfare of the marginalized people. The policy instrument is the tax rate. To facilitate the analysis in the following the indirect utility function of the marginalized is utilised.

\subsection{National tax policy}

For any given parameter $\gamma$ and $\tau$ the local government maximizes the utility function of the unemployed by choosing an appropriate value of tax rate $t$.

$$
V(\tau, \gamma, p)=\arg \max _{t} 2\left[\frac{S_{n}(t, \tau, \gamma, p)}{p_{n}(\tau)}\right]^{1 / 2} .
$$

Result 1 is summarized as follows.

Result 1. (Tax policy) (a) The optimal tax rate is $t^{*}=1 / 2-\gamma \tau / 2 p$. (b) The tax rate is $t^{*}=1 / 2$, if $\gamma=0$.

\footnotetext{
${ }^{6}$ For a detailed analysis of the measurement of multidimensional poverty, see Bourguignon and Chakravarty (2003).
} 
Proof: The first-order condition is given by

$$
\frac{\partial V}{\partial t}=\frac{c_{n}^{-1 / 2} e(w(\tau))^{2}}{p_{n}(\tau) n(p+\gamma \tau)^{2}}\left(p-\gamma \tau-2 t^{\star} p\right)=0 .
$$

The solution to the welfare optimization problem is represented by the tax rate $t^{\star}$. The sign of the last expression depends on the sign of $\left(p-\gamma \tau-2 t^{\star} p\right)$. This term is a monotonically decreasing function of $t$. As $t$ goes to zero it attains $(p-\gamma \tau)$, which is positive owing to the assumptions $\tau<p$ and $\gamma \in[0,1]$. On the other hand, it achieves $-(\gamma \tau+p)<0$ as t goes to 1 . Avalue of the tax rate exists $t^{\star} \in(0,1)$ for which $V$ is maximized.

As can be seen from Result 1 , if globalization is increasing, i.e. $\tau$ decreases, the optimal tax rate increases. Tax policy as a redistributive instrument is a constant rule, i.e. $t^{\star}=1 / 2$, when tariff revenues are fully redistributed to the employed. Given the values of $\gamma$ and $\tau$ the government chooses the tax rate in such a way that it maximizes the per capita transfer to the unemployed. As the higher value of the tax rate is chosen it earns a higher amount of tax revenue. But for the employed person as the tax rate goes up and his/her post tax wage falls, a substitution effect dominates an income effect. Therefore he/she reduces their labour supply. Consequently income and tax revenues fall.

While choosing the optimum tax rate the national government balances two countervailing forces, the marginal benefit and the marginal cost. It settles at the tax rate $t^{*}=1 / 2-\gamma \tau / 2 p<1 / 2$. If $\gamma$ increases the employed receive a lower share of the tariff revenue. Therefore it acts as an additional tax on the employed persons. An increase in the value of $\gamma$ intensifies the substitution effect. Thus the marginal cost from choosing the higher tax rate becomes magnified. Therefore as $\gamma$ increases the government chooses a lower value of $t^{\star}$. If $\gamma=0$, it chooses the highest optimal possible value of the tax rate which is $t^{\star}=1 / 2$.

The value of the tariff rate $\tau$ also influences the choice of $t^{\star}$ exactly in the same way as $\gamma$. As increases the consumption of imports of employed people becomes more costly. As with $\gamma$, it also magnifies the marginal cost. However the opposite happens if the value of $\tau$ falls. Given $\gamma>0$, the marginal cost of choosing the higher tax rate for the government falls for a given marginal benefit. The tax authority chooses a higher tax rate.

Imports and tariff revenues provide the domestic government with the opportunity to increase the tax rate to maximize the welfare of the marginalized of the economy. Note: if $\gamma=0$, this effect does not work. In this situation the government redistributes the entire amount of tariff revenue to the employed persons only. Therefore the change in tariff rate no longer influences the marginal cost of taxation. The government keeps the tax rate unchanged even if the tariff rate falls as the economy becomes more integrated in global markets. 


\subsection{Relative inequalities}

Now the effect of globalization on relative income and relative consumption inequality in the economy is explored. $R_{c}$ is the ratio of equilibrium consumption of both groups, $R_{c}=c_{e} / c_{n}$. Furthermore $R_{y}$ is the ratio of income of the employed and unemployed in equilibrium, $R_{y}=y_{e} / y_{n}$. A higher value of $R_{c}$ stands for the relative higher inequality in the economy. Similarly a higher value of $R_{y}$ stands for higher relative income inequality in the economy.

By substituting the value of $t^{*}$ in per capita consumption and income the equilibrium values $R_{c}$ and $R_{y}$ are obtained. The consumption ratio is

$$
R_{c}=\frac{n}{e} \cdot \frac{p_{n}(\tau)\left(1-t^{\star}\right)}{\left(t^{\star} p+\gamma \tau\right)} .
$$

Similarly from the income ratio the result is

$$
R_{y}=\frac{n}{e} \cdot \frac{p_{n}(\tau)\left(1-t^{\star}\right)(p+\tau)}{\left(t^{\star} p+\gamma \tau\right)} .
$$

The income ratio can be rewritten as

$$
R_{y}=R_{c}(p+\tau)
$$

Now it is possible to examine how the inequalities in relative income and consumption, $R_{y}$ and $R_{c}$, change as globalization increases, i.e. the tariff rate $\tau$ decreases.

Result 2. (Relative inequalities) (a) As globalization increases inequality in relative consumption, $R_{c}$, rises. (b) As globalization increases, relative income inequality $R_{y}$ rises if and only if the elasticity of the non-trade commodity price $p_{n}$ with respect to the tariff rate is high, i.e. $\epsilon>\tau /(p+\tau)$. If the value of $\epsilon$ is low, income inequality will decrease.

Proof: (a) From consumption ratio the result is

$$
\frac{\partial R_{c}}{\partial \tau}=\frac{n}{e}\left[\frac{-p_{n}(\tau)(p+\gamma \tau) d t^{\star} / d \tau-\left(1-t^{\star}\right) \gamma}{\left(t^{\star} p+\gamma \tau\right)^{2}}+\frac{1-t^{\star}}{t^{\star} p+\gamma \tau} \frac{d p_{n}}{d \tau}\right] .
$$

Note: by assumption (A.2) $\partial p_{n} / \partial \tau<0$. If $\gamma=0$, Result 1 implies $\partial t^{\star} / \partial \tau=0$. Since $t^{\star} \in(0,1)$ it follows

$$
\frac{\partial R_{c}}{\partial \tau}=\frac{n}{e} \cdot \frac{\left(1-t^{\star}\right)}{t^{\star} p} \frac{d p_{n}}{d \tau}<0
$$


If $\gamma>0$, Result 1 implies $\partial t^{\star} / \partial \tau=-\gamma / 2 p$. Substituting this value of $\partial t^{\star} / \partial \tau$ yields

$$
\frac{\partial R_{c}}{\partial \tau}=\frac{n}{e} \cdot \frac{\left(1-t^{\star}\right)}{\left(t^{\star} p+\gamma \tau\right)} \frac{\partial p_{n}}{\partial \tau}<0 .
$$

The statement of the first part of the claim follows.

(b) From $R_{y}=(p+\tau) R_{c}$ one can derive

$$
\frac{\partial R_{y}}{\partial \tau}=(p+\tau) \frac{\partial R_{c}}{\partial \tau}+R_{c}
$$

Substituting the value $R_{c}$ of and the value of $\partial R_{c} / \partial \tau$ the result is

$$
\frac{\partial R_{y}}{\partial \tau}=\frac{n}{e} \cdot \frac{\left(1-t^{\star}\right)}{\left(t^{\star} p+\gamma \tau\right)} \frac{(p+\tau) p_{n}}{\tau}\left(\frac{\tau}{p+\tau}-\epsilon\right) .
$$

Therefore the claim of the second part of Result 2 follows.

Inspection of Result 2 leads to the following claim. As the economy is more globalized, induced by an exogenous reduction in the tariff rate and an induced increase in international trade, the relative consumption inequality within the economy rises even if the government focuses exclusively on the maximization of the welfare of the marginalized. However it also shows that depending on the elasticity of the non-traded commodity price with respect to the tariff rate, as the economy is more globalized, it may well be the case that the relative income inequality within the economy falls. As a consequence of more globalization, which means a decrease in the value of $\tau$, if the price of the non-traded commodity which is consumed by the unemployed only does not rise too much, i.e. if the value of the price elasticity is fairly low, then Result 2 predicts a fall in income inequality. This observationis noted separately.

Corollary. Assume a small open economy. A welfare programme for marginalized people in the economy cannot fully compensate for the loss in utility suffered by an increase in globalization.

\section{Conclusions}

Has globalization led to a greater inequality or less inequality between nations and within nations? Empirical economic research confirms that income inequality has widened in both rich and poor countries over recent decades at different speeds. For example European economic integration has led to a narrowing of equality of income across countries, but an increase in inequality within countries. 
This paper has discussed the relationship between an increase in globalization and relative income and consumption inequality within a country. If the economy is going to be more globalized and when the government exclusively maximizes the welfare of the marginalized people in the economy, although the consumption inequality always rises, the income inequality may fall in certain circumstances. As a consequence of more globlization, which means a decrease in the tariff rate, if the price of the non-traded commodity, which is consumed by the unemployed does not rise too much, i.e., if the price elasticity is fairly low, then a fall in relative income inequality is predicted.

\section{References}

Alvaredo, F., Chancel, L., Piketty, T., Saez, E., \& Zucman, G. (2018). World inequality report 2018. Retrieved from: wir2018.wid.world

Atkinson, A. B. (2015). Inequality. What can be done?. Cambridge, MA: Harvard University Press.

Baldwin, R., \& Wyplosz, C. (2015). The economics of European integration (5th ed.). London: McGraw Hill.

Basu, K. (2006). Globalization, poverty and inequality: What is the relationship? What can be done?. World Development, 34, 1361-1373.

Basu, K. (2011). Groundwork for a new economics. Princeton, NJ: Princeton University Press.

Bourguignon, F., \& Chakravarty, S. R. (2003). The measurement of multidimensional poverty. Journal of Economic Inequality, 1, 25-49.

Elbers, C., Lanjouw, P., Mistiaen, J. A., \& Ölzer, B. (2008). Reinterpreting between group inequality. Journal of Economic Inequality, 6, 231-246.

Jomo, K. S. \& Baudot J. (Eds.). (2007). Flat world, big gaps: Economic liberalization, globalization, poverty and inequality. London: Zed Books.

OECD. (2015). In it together: Why less inequality benefits all. Paris: OECD Publishing. Piketty, T. (2014). Capital in the twenty-first century. Cambridge, MA: Belknap Press of Harvard University Press.

Rodrik, D. (2011). The globalization paradox: Democracy and the future of the world economy. New York: Norton. 